\title{
GENERAL DISCUSSION ON HYDRATES IN SOLUTION
}

At the Meeting of the Society held on Tuesday, June 25, 1907, a General Discussion on Hydrates in Solution took place. Professor S. P. U. Pickering, F.R.S., was in the chair.

\section{THE THERMOCHEMISTRY OF ELECTROLYTES IN RELATION TO THE HYDRATE THEORY OF IONISATION.}

Mr. W. R. Bousfield, M.A., K.C., and Dr. T. Martin Lowry contributed a Paper on "The Thermochemistry of Electrolytes in Relation to the Hydrate Theory of Ionisation."

I. Energy-Changes Accompanying the Ionisation of a Salt.

One of the fundamental difficulties of the theory of electrolytic dissociation is to discover a motive force adequate to account for the separation in aqueous solutions of elements so strongly attractive of one another as, for instance, potassium and chlorine. This difficulty undoubtedly forms the chief hindrance to the universal acceptance of the theory, and is in no way decreased by the fact that the atoms of potassium and chlorine are assumed to acquire in the act of separation equal and opposite electric charges. These charges would certainly increase rather than diminish the mutual attraction of the metal and non-metal, and though the electrical forces would be much less in a highly inductive medium like water (s.i.c. $=80$ ) than in air (s.i.c. $=\mathrm{I}$ ) or ether (s.i.c. $=4$ ), the mere weakening of the electrical attraction affords no explanation of the disappearance of the powerful chemical affinity between the two elements. These difficulties have been repeatedly urged by Armstrong and others, and have not as a rule received any direct or convincing answer.

The difficulty was accentuated when Arrhenius (Zeit. phys. Chem., I889, 4 , 104), by making use of van't Hoff's relationship,

$$
\frac{d \log k}{d \mathrm{~T}}=\frac{q}{2 \mathrm{~T}^{2}}
$$

actually determined the heat changes involved in the ionisation or electrolytic dissociation of a number of acids, bases, and salts, and found that in a large number of cases the process was accompanied by a liberation of heat.

Nernst (Theoretical Chemistry, English translation, 1895, p. 562; I904, p. 659), quoting the results of Arrhenius, observes: "In this way the result was ascertained that the dissociation of a substance into its ions is usually attended with a development of heat." Arrhenius himself points out that ordinary dissociation is normally accompanied by absorption of heat, and in justification of the apparent anomaly in the case of electrolytic dissociation observes that: "One case of ordinary dissociation is known in which the decomposition is accompanied by liberation of heat. If two gram-molecules of ozone $\left(\mathrm{O}_{3}\right)$ are converted into three gram-molecules of oxygen $\left(\mathrm{O}_{2}\right)$, the change is accompanied by the development of not less than 30,000 cal."

This case has, however, but little direct bearing on the problem under 
consideration. The conversion of two molecules of ozone into three molecules of axygen $2 \mathrm{O}_{3} \rightleftarrows 3 \mathrm{O}_{2}$ is not a dissociation in the same sense as the conversion of one molecule of nitrogen tetroxide into two molecules of the dioxide $\mathrm{N}_{2} \mathrm{O}_{4} \longleftrightarrow{ }_{2} \mathrm{NO}_{2}$, or the conversion of a molecule of chlorine or iodine into two separated atoms $\mathrm{I}_{2} \rightleftarrows 2 \mathrm{I}$. In all such cases in which the decomposition is accompanied by a decrease of valency or the formation of free bonds, the dissociation appears to be endothermic and the association exothermic.

But the "dissociation" of ozone into oxygen is merely a conversion of one complex into another, and may be compared with the so-called "dissociation" of hydrogen iodide,

$$
2 \mathrm{HI} \rightleftarrows \mathrm{H}_{2}+\mathrm{I}_{2}+6,000 \text { cal., }
$$

in which two similar diatomic molecules interact to form two dissimilar molecules. In such a case the sign of the heat-change depends on the relative magnitude of the three affinities concerned, viz., $\mathrm{H}-\mathrm{H}, \mathrm{I}-\mathrm{I}$, and $\mathrm{H}-\mathrm{I}, *$ and if the homogeneous molecules possess a higher stability than the heterogeneous, the "dissociation" will naturally be exothermic. So also in the case of ozone and oxygen the sign of the heat-change will depend on the relative stability of the triatomic and diatomic complexes, and there is, therefore, no a priori reason why the change from ozone to oxygen should not be exothermic.

The case of ionic dissociation stands on quite a different footing since the ions are always assumed, when elementary, to consist of single atoms bearing positive or negative charges. There is, therefore, no affinity of atom for atom on the right-hand side of the equation to account for a liberation of heat in the change-

$$
\mathrm{KCl}=\stackrel{+}{\mathrm{K}}+\overline{\mathrm{Cl}}+250 \text { cal. ; }
$$

on the other hand, it is well known that the formation of a molecular proportion of potassium chloride from its elements involves the liberation of a large quantity of heat, and that an equal amount would be absorbed in the decomposition of the salt into molecular potassium and molecular chlorine-

$$
\mathrm{KCl}=\frac{\mathrm{K} x}{x}+\frac{\mathrm{Cl}_{2}}{2}-105,600 \text { cal. }
$$

The decomposition into separate atoms of the molecules of potassium and chlorine would involve a further absorption of heat, and since the electrification of the naked atomts can scarcely be other than an endothermic process, the change represented by the symbols $\mathrm{KCl}=\stackrel{+}{\mathrm{K}}+\overline{\mathrm{Cl}}$, so far from causing the liberation of 250 calories, must actually involve the absorption of more than I00,000 calories!

The extraordinary discrepancy between these two values appears to us to indicate that the process of ionisation cannot consist merely of a separation of the molecule into its constituent atoms even though these may be endowed with electrical charges, and we are driven to assume that the essentially endothermic process of dissociation must be balanced by some powerful exothermic action, associative rather than dissociative in its character.

* Thomsen, Thermochenische Untcrsuchungen, vol. ii. p. 2.

$\dagger$ Arrhenius, Zeit. phys. Chem., I889, 4, J06. A different value is given in a later paper (Zit. phys. Chem., 1892, 9, 340); there appears to be much uncertainty as to the actual value of the heat-change, but the order of magnitude is all that need be noted for the purpose of the present argument. Nernst's generalisation as to the sign of the heat-change is supported by the fact that the coefficient of ionisation normally decreases with rising temperature, although the conductivity may increase (Bousfield and Lowry, Proc. Roy'. Soc., I902, 71, 42). 


\section{Water-Combination as a Source of Energy in Ionisation,}

The general nature of this exothermic process was indicated many years ago by Fitzgerald, who (in opposition to the statements of Ostwald and others, that the solvent was quite inactive in electrolytic dissociation and served merely as a screen to keep separate the spontaneously-generated ions) urged that it was a great mistake to neglect the very active part that the solvent must play in the process of solution (B.A. Report, Leeds, 1890,327 ).

Solvents such as water, hydrogen cyanide, sulphur dioxide, and ammonia, which are specially active in promoting ionisation are characterised by a high degree of "residual affinity" (Armstrong, Trans. Chem. Soc., I895, 67, I 70 ; Dutoit and Aston, C.R. 1897, 125, 240 ; Brühl, Zeit. phys. Chem., I893, 27, 3 I9), and there can be little doubt that this molecular property (of which the specific inductive capacity of the liquid $*$ is perhaps a direct physical manifestation) is a factor of great importance in promoting ionisation.

These general considerations have in recent years found concrete expression in the hydrate theory of ionisation, which postulates that in aqueous solutions the energy required for the disruption of the salt molecule is derived from the combination of the solvent with the oppositely charged radicles of the salt to form complex hydrated ions. On the experimental side we were led to advocate this view of ionisation as a sequel to the study of the volume-changes which accompany the dissolution of electrolytes and the dilution of their solutions. It was pointed out (Bousfield and Lowry, Phil. Trans., I904, Ser. A, 204, p. 282) that the notable contraction which takes place on the solution of an electrolyte must be attributed to watercombination, and that in the case of sodium hydroxide contraction and ionisation go on pari passu, from which the conclusion was drawn that water-combination and ionisation are intimately connected, possibly even as cause and effect. In the case of caustic soda, the contraction is so great as to indicate the existence of extremely powerful forces at work in the solution, and there can be little doubt that residual affinity may in many instances constitute a most important reservoir of energy. In two subsequent papers (Bousfield, Zeit. phys. Chem., 1905, 53, 257 ; Phil. Trans., 19o6, ser. A, 206, 127) the matter has been further developed by one of us, especially with reference to $\mathrm{KCl}$ and $\mathrm{NaCl}$, and it has been shown that the mobilities of the ions afford important evidence in favour of the theory of water-combination; it has even been found possible to obtain figures representing the variations in the volume of the ion as the concentration of the solution (and therefore the degree of hydration) changes, and it has been shown that the ionic volumes deduced in this way are connected by a linear relation with the solution volumes, or, in other words, with the contraction of the solution.

According to the view which we advocate, the combination of the charged radical, or ionic nucleus,

$$
\stackrel{+}{\mathrm{Na}}, \overline{\mathrm{Cl}}, \stackrel{+}{\mathrm{M} g}, \overline{\mathrm{SO}} \overline{\mathrm{H}}_{4}, \& \mathrm{c} .,
$$

with water is a powerful exothermic process, and the affinity of the ionic nucleus for water is the main source of the disruptive force which breaks down or ionises the molecule: the heat liberated in this way is of the same order of magnitude as the heat absorbed by the disruption of the molecule, and the balance may be either a small positive or a small negative quantity.

- For the relationship between s.i.c. and ionisation on the theoretical side, see J. J. Thomson, Phil. Mas., v., 36, 320 ; Nernst, Zcit. phys. Chem., r893, Ir, 220; on the experimental side, see Walden, Zeit. plys. Chem., I906, 54, I3I. 


\section{I26 THE THERMOCHEMISTRY OF ELECTROLYTES IN}

The evidence in favour of the hydrate theory of ionisation has been summarised by one of us in a previous paper communicated to the Society and published in its Transactions (Lowry, Trans., 1905, 1, 197), and more recently by Senter (Science Progress, Jan., 1907, pp. 38I-399).

\section{ENERgY of Electrification of Ions.}

In explaining the exothermic character of the process of ionisation by the view that an ion is an "allotropic" form of an element, Ostwald (B.A. Report, Leeds, 1890 ), appears to have harboured the idea that the electrification of an element may perhaps be a source of energy. The same idea is implied in the title and in many expositions of Abegg and Bodländer's theory of electro-affinity.**

Now, it may be recognised that the different elements exhibit a preference for electrical charges of one sign or the other, so that chlorine is more easily charged with negative than with positive electricity, whilst the opposite is the case with potassium ; but we are of opinion that the electrification of an atom is an operation which is normally accompanied by an absorption rather than by a liberation of energy, and that the process of separating from one another the opposite charges of an anion and kathion cannot possibly be other than an endothermic action. In order to illustrate this point we have made a rough calculation from the known values of the ionic charge and the ionic radius of the work required to electrify one equivalent of kathion or anion on the assumption that the ions may be regarded as charged spheres immersed in a fluid dielectric.

The calculation may be carried out in the following three stages:

(I) The electrostatic capacity of a spherical conductor when widely separated from other conductors $\dagger$ is given by the formula

$$
c=r k \text {, }
$$

where $r$ is the radius of the sphere and $k$ the s.i.c. of the surrounding medium. The energy of the sphere when electrified with a charge $q$ is

$$
e=\frac{q^{2}}{2 r k}
$$

(2) In order to apply this formula to the ions it is necessary to deduce values for the ionic charge $q$ and the ionic radius $r$. If $n$ is the number of ions in a gram-equivalent $\ddagger$ the ionic charge $q$ in electrostatic units is given by the formula

$$
q=\frac{Q}{n} \times 3 \times 10^{9},
$$

where $Q$ is the charge in coulombs carried by one gram-equivalent of ions, the factor $3 \times 10^{9}$ being introduced to bring the coulombs to e.s. units.

A value for the ionic radius may be deduced by assuming that the motion of an ion in an electrolyte is governed by Stokes's Law for the movement of a

* "The alkali metals have the greatest affinity for positive electricity, while such metals as mercury, platinum, and gold have very little" (Science Progress, January, Iȳ7, p. I5).

$t$ The ions in a solution cannot, of course, be considered to be widely separated ; but the same conditions will exist if each ion is equally influenced by a large number of positive or negative ions distributed through the surrounding medium, or, in other words, if its potential is not controlled by the immediate contiguity of one other ion of the same or of opposite sign.

$\ddagger$ About $6 \times 10^{23}$; this figure, which represents the number of molecules in a gram-molecule of any substance, is eliminated in the subsequent calculations. 
sphere in a viscous medium. According to this law the radius is given by the expression

$$
r=\frac{\mathrm{F}}{6 \pi \mu v}, *
$$

where $\mu$ is the viscosity of the medium,

$F$ the force acting on the sphere,

and $v$ its limiting velocity.

The force acting on a charge $q$ in a field of $\mathrm{I}$ volt per centimetre is $\frac{q}{300}$ dynes, if $q$ is in electrostatic units, the factor $\frac{I}{300}$ being introduced in order to convert the potential gradient into the same system of units. The limiting velocity of an ion moving under this potential gradient is $v=\frac{l}{\mathrm{Q}} \mathrm{cms}$. per sec., where $l$ is the ionic mobility and $Q$ the charge of 96,540 coulombs carried by one gram-equivalent. $\dagger$

The viscosity of water may be taken as $\mu=0^{\circ}$ or and the ionic radius is then

$$
\begin{aligned}
r= & \frac{Q \times 3 \times 10^{9}}{300 n} \times \frac{\mathrm{I}}{6 \pi \times 10^{-2}} \times \frac{Q}{l} \\
= & \frac{Q^{2}}{n l} \times \frac{109}{6 \pi}
\end{aligned}
$$

(3) Having thus deduced expressions for the ionic charge and the ionic radius, it is possible to obtain a value for the energy of electrification of an ion by substituting these expressions for $q$ and $r$ in the formula given above in paragraph ( $\mathrm{I}$ ). This gives for a single ion the energy of electrification

$$
\begin{aligned}
e=\frac{\phi^{2}}{2 r k} & =\frac{Q^{2} \times 9 \times 10^{18}}{2 n^{2} k} \times \frac{n l \times 6 \pi}{Q^{2} \times 10^{9}} \\
& =27 \pi \times 10^{9} \times \frac{l}{n k}
\end{aligned}
$$

and for a gram-equivalent of ions

$$
E=n e=27 \pi \times 10^{9} \times \frac{l}{k} \text { ergs ; }
$$

or, expressed in heat units,

$$
E=\frac{27 \pi \times \mathrm{IO}^{9}}{42 \times 10^{7}} \frac{l}{k}=2,000 \frac{l}{k} \text { calories. }
$$

For water $k$ has the value 80 and the work done in electrifying one equivalent of ions is given as

$$
\text { I25l calories, }
$$

where $l$ is the mobility of the ion determined in the ordinary way.

The following are typical values for the heats of electrification of ions in calories per gram-equivalent as deduced from the above formula :

* Compare a former paper, Bousfield, Zeit. phys. Chem., I905, 53, 302, where Prof. Poynting's calculations for $\mathrm{KCl}$ are given.

$\dagger$ For potassium or chlorine this gives $v=6 \times 10^{-4} \mathrm{cms}$. per sec.

VOL. III-T5* 


\section{I28 THE THERMOCHEMISTRY OF ELECTROLYTES IN}

TABLE I.

\begin{tabular}{|c|c|c|c|c|}
\hline$(3 \mathrm{I} 8)$ & 7,950 & $\overline{\mathrm{Cl}}$ & $\left(65^{\circ} 9\right)$ & 1,650 \\
\hline (I74) & $4,35^{\circ}$ & $\overline{1}$ & $(66 \cdot 7)$ & I,67o \\
\hline$\left(65^{\circ} 3\right)$ & $1,64^{\circ}$ & $\stackrel{+}{2} \stackrel{+}{\mathrm{Ba}}$ & $(57 \cdot 3)$ & $1,43^{\circ}$ \\
\hline$(44 \cdot 4)$ & I, I IO & $\frac{1}{2} \overline{\mathrm{SO}}$ & $+(697)$ & $\mathrm{I}, 74^{\circ}$ \\
\hline
\end{tabular}

The numbers in brackets are the ionic mobilities.

It should be noticed that these values are based on two assumptions :

(I) That the ordinary formulae for the electrostatic capacity and energy of electrification of a spherical conductor may be applied to the ions: and

(2) that their motion through the liquid is governed by Stokes's Law, the ions being spherical and having all the same coefficient of friction.

In addition, the numerical value of Joule's equivalent has been assumed, but it has not been necessary to assume any numerical value for the actual mass or volume of the ion, as these do not enter into the formula finally arrived at. Both the above assumptions are open to discussion, and the calculation is given mainly in order to emphasise the essentially endothermic character of the process by which atoms are converted into ions.

It will also be noticed that the above calculation is based on the supposition that the electric charge is distributed over the surface of the ionic complex, the energy of electrification being proportional to the mobility and therefore, on our hypothesis, inversely proportional to the radius of the ion which carries the charge. If, therefore, the charge is confined to the nucleus, or if (as the electronic theory suggests) it is localised in one or more centres corresponding with the valencies of the radical, the energy of electrification would probably be greater than we have supposed, and especially so in the case of the polyvalent ions.

The data made use of above may also be employed to calculate values for the work done in separating two charged ions, as, for instance, during the ionisation of a neutral salt. For the purposes of this calculation it will be convenient to make an alternative assumption, viz., that the ionic charge is concentrated at the centre of the sphere, which would be approximately the case if the ionic nucleus were charged and not the surrounding "watery atmosphere." The work done in separating to a great distance* a pair of ions of equal radii already endowed with equal and opposite charges from an initial position in which the distance between their centres is practically equal to the sum of the radii is then given by the same expression,

$$
\frac{q^{2}}{2 r k}
$$

as was deduced above for the energy of electrification of a single ion. The work so reckoned is therefore one-half the total work of electrification as reckoned by the first method. As, however, the second method leaves out of account the work done in the initial separation of the + and - charges, it is perhaps better to adopt the value tabulated above for the total energy of electrification, rather than the half-values which (on an alternative hypothesis as to the distribution of the charge) represent the work done in separating the previously-charged ions.

\footnotetext{
* See footnote + on page 4 .
} 


\section{Heats of Formation of Ions.}

We propose next to consider the heats of formation of the separate ions from the standpoint of the hydrate theory of ionisation.

In the case of several of the metallic ions and a small number of nonmetallic ions, values have been deduced by Ostwald and others for the actual heat-changes involved in the conversion of the elements into ions or vice versâ. These values have been obtained by the study of electrode potentials.

To take an illustration. When zinc dissolves in dilute sulphuric acid the action is conventionally represented by the equation :-

$$
\mathrm{Zn}+\mathrm{H}_{2} \mathrm{SO}_{4} \mathrm{aq}=\mathrm{H}_{2}+\mathrm{ZnSO}_{4} \mathrm{aq}+38,700 \mathrm{cal} \text {. }
$$

According to the theory of Arrhenius, however, the acid and salt are, in dilute solution, resolved into their ions and the equation may therefore be written-

$$
\begin{array}{ll}
\text { or simply- } & \mathrm{Zn}+2 \stackrel{+}{\mathrm{H}}+\overrightarrow{\mathrm{SO}_{4}}=\mathrm{H}_{2}+\stackrel{+}{\mathrm{Zn}^{+}}+\overrightarrow{\mathrm{SO}_{4}} \\
& \mathrm{Zn}+2 \stackrel{+}{\mathrm{H}}=\mathrm{H}_{2}+\stackrel{+}{\mathrm{Z}_{n}^{+}}+38,700 \mathrm{cal} .
\end{array}
$$

The energy changes involved are those due to the conversion of zinc-metal into zinc ions-

$$
\mathrm{Zn} \longrightarrow \stackrel{+}{\mathbf{Z}} \mathbf{n}
$$

and conversely of hydrogen ions into hydrogen gas-

$$
2 \stackrel{+}{\mathrm{H}} \rightarrow \mathrm{H}_{2} \text {. }
$$

The energy change is therefore the difference between the heats of formation of zinc ions and of hydrogen ions from these elements in their normal condition.

In a single-fluid cell the ionisation of the zinc and the deionisation of the hydrogen take place at the two electrodes and produce there two abrupt changes of potential. If these potential-differences, $P$, and their temperature coefficients are known, it is possible to calculate the heat values $Q$ corresponding with the two changes by means of the equation-

$$
\mathrm{P}=\frac{\mathrm{Q}}{23,07 \mathrm{O}}+\mathrm{T} \frac{d \mathrm{P}}{d \mathrm{~T}}
$$

(Arrhenius, Electrochemistry, p. $23^{8}$ ).

Unfortunately, there is no general method known by which the actual potential differences between the metals and their solutions can be separately determined. All the practical methods of measurement necessitate the use of two electrodes and the figures obtained represent in all cases the sum (or difference) of at least two electrode-potentials. Thus in the Daniell cell the E.M.F. is due to the energy of ionisation of zinc plus the energy of deionisation of copper; the E.M.F. of a simple fluid cell is due to the energy of ionisation of zinc plus the energy of deionisation of hydrogen; and similar considerations apply when a calomel electrode is used. 'The separate values given by Ostwald are therefore based on an independent determination of the absolute p.d. in the case of the calomel electrode. This absolute determination, 0.56 volts for a normal $\mathrm{KCl}$ solution, depends on a study of capillary mercury electrodes, in which the electrical forces are balanced against surface tension, and is admittedly not of a very high degree of accuracy. 


\section{r30 THE THERMOCHEMISTRY OF ELECTROLY'TES IN}

Other sources of error are due to the incomplete ionisation of the metallic salts and the difficulty of determining the temperature-coefficients $\frac{d \pi}{d \mathrm{~T}}$. The heats of ionisation shown in the following table * (Lehrbuch allg. Chem., "Elektrochemie," p. 955) are therefore given by Ostwald as subject to an error of $\pm r, 000$ calories. The numbers refer in all cases to the heats of ionisation per equivalent :-

TABLE II.

\begin{tabular}{|c|c|c|c|c|c|}
\hline ....... & 61,200 & $\frac{1}{2} \mathrm{Fe} \ldots . .$. & 10,100 & Hg....... & $-20,700$ \\
\hline $\mathrm{Na} . . . .$. & $5^{6,500}$ & $\frac{1}{3} \mathrm{Fe} . . . .$. & $-12,100$ & Ag...... & $-26,400$ \\
\hline $\mathrm{Li} \ldots . .$. & 62,200 & Co....... & 7,600 & Ti ...... & 800 \\
\hline$\frac{1}{2} \mathrm{Gr} . . . .$. & 58,000 & $\mathrm{Ni} . . . .$. & 7,000 & $\frac{1}{2} \mathrm{~Pb} . . . .$. & - \\
\hline$\frac{1}{2} \mathrm{Ca}$ & 53,800 & $\mathrm{Zr}$ & 16,600 & $\frac{1}{2} \mathrm{Sn} . .$. & + \\
\hline$\frac{1}{2} \mathrm{Mg} . . . .$. & 53,600 & $\mathrm{Cd} . . . .$. & 8,300 & $\mathrm{Cl}$. & 39,900 \\
\hline$\frac{1}{3} \mathrm{~A} 1 .$. & 39,400 & $\frac{1}{2} \mathrm{Cu} \ldots . .$. & $-8,900$ & $\mathrm{Br}$. & 28,900 \\
\hline$\frac{1}{2} \mathrm{Mn} .$. & 24,200 & $\mathrm{Cu} \ldots \ldots$. & I $7,000(?)$ & I & 13,70 \\
\hline
\end{tabular}

5. Heats of Formation of Salts in Dilute Solution as Related to THE HEATS OF FoRMation OF IONS.

A second method of determining the heats of formation of the ions appears to be less generally recognised, since it is not definitely described in the standard text-books, $\nmid$ although it seems to have been used by Ostwald in compiling the above table. The method depends on the fact that according to the theory of electrolytic dissociation the heat of formation of a salt in dilute solution is made up of the sum of the heats of formation of the ions.

To take an illustration : the preparation of a dilute solution of potassium chloride from potassium and chlorine may be represented as taking place in two stages :

(I) The preparation of solid molecular potassium chloride from potassium metal and chlorine gas, a process which involves a small absorption of heat in decomposing the molecules of potassium and chlorine and a large liberation of heat in the formation of molecules of potassium chloride from the atoms of potassium and chlorine-

$$
\frac{\mathrm{I}}{x} \mathrm{~K}_{x}+\frac{\mathrm{I}}{2} \mathrm{Cl}_{2}=\mathrm{KCl}+\mathrm{IO}_{5}, 600 \mathrm{cal} .
$$

This process is strongly exothermic.

(2) The dissolution of the salt in a large quantity of water, whereby the solid molecular potassium chloride becomes completely ionised-

$$
\mathrm{KCl}+\mathrm{aq}=\stackrel{+}{\mathrm{K}} \mathrm{aq}+\overline{\mathrm{C}} \mathrm{aq}-4,400 \mathrm{cal} .
$$

This process is slightly endothermic.

On the other hand, these two processes may be combined into one equation-

$$
\frac{\mathrm{I}}{x} \mathrm{~K}_{x}+\frac{\mathrm{I}}{2} \mathrm{Cl}_{2}+\mathrm{aq}=\stackrel{+}{\mathrm{K}} \mathrm{aq}+\overline{\mathrm{Cl}} \mathrm{aq}+\text { IOr,200 cal., }
$$

in which is shown the energy required to convert one equivalent of molecular chlorine and one equivalent of molecular potassium into hydrated

* It may be noted that Arrhenius gives the opposite sign to heats of ionisation, which means that he takes heat of ionisation to signify heat absorbed by ionisation. It seems preferable, however, to follow Ostwald's nomenclature and take heat of ionisation as heat developed by ionisation and therefore as heat of formation of ions.

$\dagger$ Arrhenius (Electrochemistry, p. 239) describes a method by which the thermal data may be used to calculate the heats of ionisation of metals from the heats liberated when they are dissolved in acids, but makes no mention of the heats of formation of the non-metallic ions. 
ions. This process is strongly exothermic, and it will be seen that the intermediate formation and dissociation of molecular potassium cliloride have been entirely eliminated, so that the final heat-balance depends solely on the energy set free during the conversion of the two elements into their hydrated ions.

The heats of formation of a large range of salts have been determined with a high degree of accuracy by Thomsen and others (Thermochemische Untersuchungen, Leipzig, 1882; Landolt and Bornstein, PhysikalischChemische Taballen, pp. $427-45^{8}$ ), and ample data are therefore available for the calculation of the heats of formation of most of the important ions.

Unfortunately, this method shares with that described in the previous section the disadvantage that the experimental data give values involving two heats of ionisation which cannot be measured separately. Thus whilst it is clear that the total heat of formation of one equivalent of potassium ions and one equivalent of chlorine ions amounts to Ior,200 calories, it is not clear how this is to be divided in order to give the heats of formation of the two ions separately. We were at first inclined, in the special case of potassium chloride, to divide the heat liberated into two equal parts (in much the same way as was done by Kohlrausch in resolving its molecular conductivity into the sum of two migration velocities) on the ground that ( $\mathrm{I}$ ) the two atomic nuclei are of nearly equal mass, and (2) the ions have equal mobilities and may, therefore, be regarded as almost equally hydrated. We prefer, however, to make use, as described in the previous section, of the absolute determination of the potential difference at a calomel electrode, and have, therefore, adopted Ostwald's figure - 600 calories as the heat of formation of one equivalent of hydrogen ions. Using this value, it is possible with the help of the heats of formation of the salts to deduce absolute values for the heats of formation of all the important ions, both positive and negative. It will be noticed that whilst the absolute values are subject to the same error as those determined from electrode potentials, the relative values are more accurate, owing to the greater ease of the operations involved and the remarkable standard of excellence attained by Thomsen in his thermochemical determinations.

We show in Tablc III. the heats of formation in dilute solution of gramequivalents of the more important acids, bases, and salts together with the differences between the values for the salts and those for the acids and bases from which they are derived.

In Table IV. are set out the mean values for the heats of formation of the separate ions, obtained by taking the value for hydrogen as -600 cal. There are also set out values for the heats of formation of the salts as calculated by adding together the heats of formation of their constituent ions. The differences between the observed and calculated values are set out in Table V.

The further heats of ionisation, shown in Table VI., are chiefly calculated for metals from the haloid salts and for acid radicals from the alkaline salts, by using the values before determined. They cannot in general be regarded as being relatively so accurate as those in Table IV.

We desire to draw particular attention to the fact, which is clearly demonstrated by the above tables, that the heats of formation of the salts int dilute solution are additive quantities. This is shown by the constancy of the differences $\mathrm{Li}-\mathrm{H}, \mathrm{Na}-\mathrm{H}, \& \mathrm{c}$, in Table III., and still more clearly by the smallness of the differences shown in Table $\mathrm{V}$. between the heats of formation experimentally determined by Thomsen for the different salts and the 


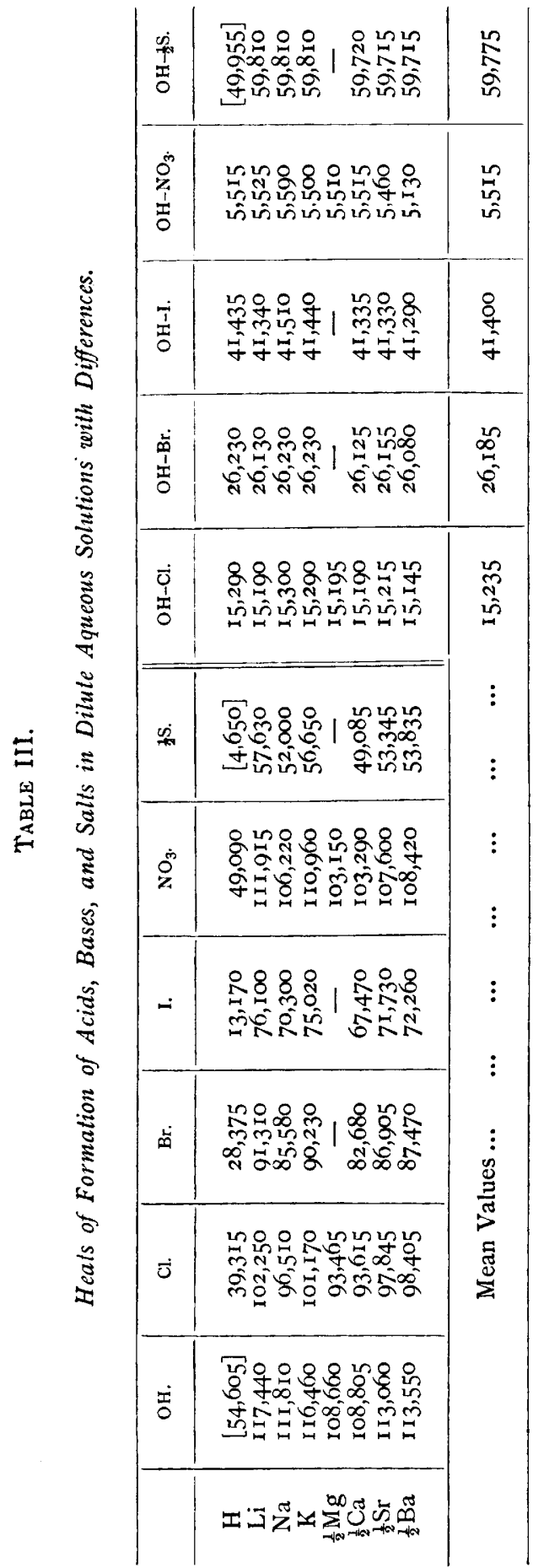

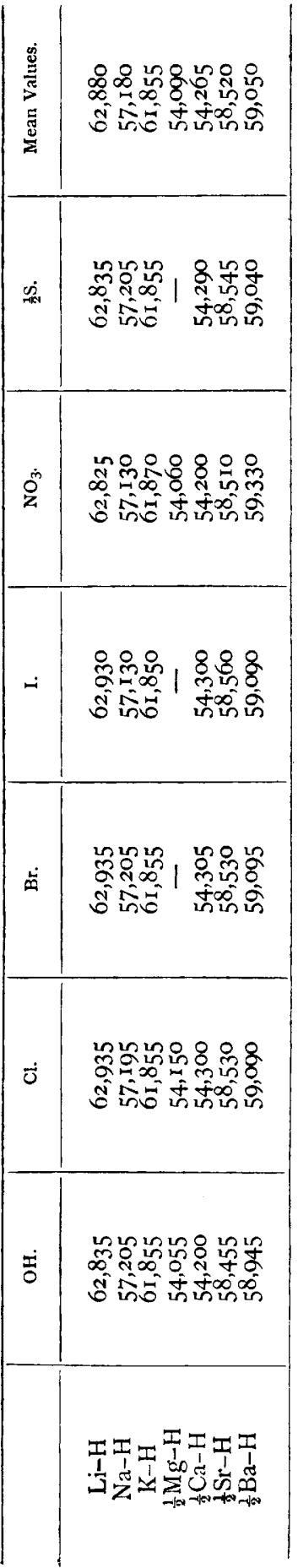


TABLE IV.

Heats of Formation of the Ions with Calculated Values for Heats of Formation of Salts.

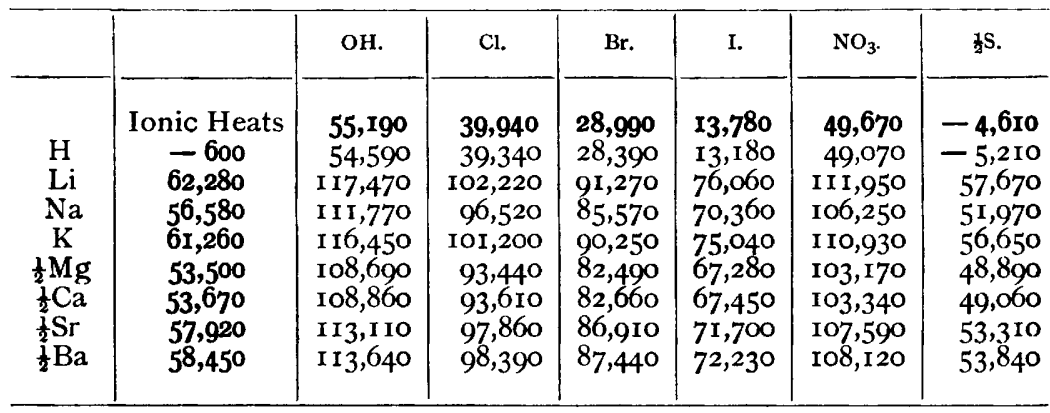

TABLE V.

Heats of Formation of Salts: Differences Between Observed and Calculated Values of Tables III. and IV.

\begin{tabular}{|c|c|c|c|c|c|c|}
\hline & OH. & Cl. & Br. & I. & $\mathrm{NO}_{3}$. & $\frac{1}{2} S$. \\
\hline $\mathrm{H}$ & $+\mathrm{I}_{5}$ & -25 & $-\mathrm{I} 5$ & -10 & +20 & {$[+9,860]$} \\
\hline $\mathbf{L i}$ & -30 & +30 & +40 & +40 & -35 & -40 \\
\hline $\mathrm{Na}$ & +40 & 一 10 & + ro & -60 & -30 & +30 \\
\hline $\mathrm{K}$ & +10 & -30 & -20 & -20 & +30 & \pm \\
\hline$\frac{1}{2} \mathrm{Mg}$ & -30 & +25 & - & - & -20 & - \\
\hline$\frac{1}{2} \mathrm{Ca}$ & -55 & +5 & +20 & +20 & -50 & +25 \\
\hline$\frac{1}{2} \mathrm{Sr}$ & -50 & -15 & -5 & +30 & + Io & +35 \\
\hline$\frac{1}{2} \mathrm{Ba}$ & -90 & +15 & +30 & +30 & +300 & -5 \\
\hline
\end{tabular}

TABle VI.

Other Heats of Formation of Ions.

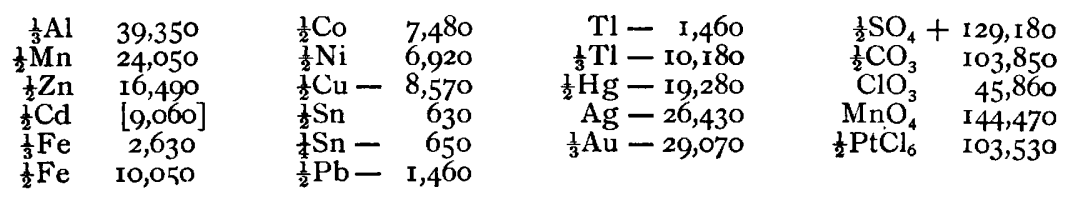




\section{I34 THE THERMOCHEMISTRY OF ELECTROLYTES IN}

values deduced by adding together the separate heats of formation of the ions. These latter are, of course, also derived from Thomsen's data by averaging the differences of Table III., but this does not affect their value as a proof of the additive character of the property in question. The striking fact is that a gram equivalent of chlorine contributes the same quota of energy to the heats of formation of potassium chloride and of calcium chloride, and that an equivalent of combined potassium represents the same amount of energy dissipated, whether it is present in the chloride, nitrate, or sulphate.

This additive relationship was to some extent recognised before Arrhenius put forward his theory of electrolytic dissociation. It is implied in Hess's law of thermo-neutrality and in Thomsen's statement (Thermochemische Untersuchungen, vol. i., pp. 12-14) that salts in dilute solution are "isodynamic." At that time, however, no explanation could be given of this remarkable law, and, indeed, it was scarcely possible even to state clearly the additive character of the heats of formation of the salts until the idea was arrived at that independent heats of formation could be attributed to the positive and negative ions or radicals of which the salts are composed. It is probably on account of this difficulty of enunciation that the relationship in question has not been more frequently quoted as evidence in support of Arrhenius's theory. Personally, we regard it as second in importance only to the additive relationship, discovered by Kohlrausch, between molecular conductivity and ionic mobility.

It is worth while to direct attention to the unique character of the additive relationship which finds its clearest expression in the law of the independent heats of formation of the ions. In the first place it should be noted that no such relationship exists in reference to the heats of formation of the solid salts nor in reference to their heats of dissolution. This is remarkable in view of the fact that fixed values for another thermal property-that of atomic heats--can only be assigned to salts in the solid state. It is also remarkable that the extraordinary difference in the behaviour towards water of salts such as potassium nitrate and chloride on the one hand, and of potassium hydroxide and calcium chloride on the other, so far from disturbing the additive law, supplies the very factor that is necessary to establish it. In other words, the additive law holds good, not for the salts themselves, but for their extreme hydrates-the hydrated ions.

In the second place attention may be directed to the fact that no such law exists amongst even the simplest organic compounds. It is true that a fictitious relationship exists between the heats of combustion, so that the replacement of $\mathrm{H}$ by $\mathrm{Cl}$ causes a decrease of 35,000 calories in the heat liberated when the compound is burnt, as is shown in the following Table VII.

TABLE VII.

Heats of Combustion of Organic Compounds.*

\begin{tabular}{|c|c|c|c|c|c|}
\hline Substance. & $\begin{array}{c}\text { Heat of } \\
\text { Combustion. }\end{array}$ & $\begin{array}{l}\text { Difference } \\
\mathrm{H}-\mathrm{Cl} \text {. }\end{array}$ & Substance. & $\begin{array}{c}\text { Heat of } \\
\text { Combustion. }\end{array}$ & $\begin{array}{c}\text { Difference } \\
\mathrm{H}-\mathrm{Cl} .\end{array}$ \\
\hline \multirow{5}{*}{$\begin{array}{ll}\mathrm{CH}_{4} \quad \ldots \\
\mathrm{CH}_{3} \mathrm{Cl} \ldots \\
\mathrm{CHCl}_{3} \ldots \\
\mathrm{CCl}_{4} \quad \ldots\end{array}$} & \multirow{3}{*}{$\begin{array}{l}21 \text { I }, 900 \\
176,900 \\
107,000\end{array}$} & \multirow{5}{*}{$\begin{array}{r}35,000 \\
2 \times 34,950 \\
31,100\end{array}$} & $\mathrm{C}_{2} \mathrm{H}_{6} \ldots \ldots$ & 370,400 & 06 \\
\hline & & & $\mathrm{C}_{2} \mathrm{H}_{5} \mathrm{Cl} \quad \ldots$ & 334,100 & \\
\hline & & & $\mathrm{C}_{2} \mathrm{H}_{4} \mathrm{Cl}_{2} \ldots$ & 296,400 & \\
\hline & \multirow{2}{*}{75,900} & & $\mathrm{C}_{6} \mathrm{H}_{6} \ldots \ldots$ & 709,300 & \\
\hline & & & $\mathrm{C}_{6} \mathrm{H}_{5} \mathrm{Cl} \quad \ldots$ & 763,900 & 35,400 \\
\hline
\end{tabular}

* Thomsen, Thermochemischc Untersuchungen, vol. iv., I886. 


\section{RELATION TO HYDRATE THEORY OF IONISATION I35}

It will be seen, however, that this relationship is only approximate, and its appearance is wholly attributable to the fact that the heats of formation of the organic compounds are negligible in comparison with the heat of combustion of the carbon and hydrogen which they contain. The decrease of 35,000 calories is, indeed, identical, within the limits of variation shown in Table VII., with the heat of combustion, 34,180 cal., of the atom of hydrogen displaced by the chlorine.

The actual heats of formation and the corresponding differences are shown in Table VIII.

Table VIIJ.

Heats of Formation of Organic Compounds.:

\begin{tabular}{|c|c|c|c|c|}
\hline Substance. & $\begin{array}{l}\text { Heat of Formation } \\
\text { of Gas. }\end{array}$ & $\begin{array}{l}\text { Difference } \\
\mathrm{Cl}-\mathrm{H} .\end{array}$ & $\begin{array}{l}\text { Heat of Formation } \\
\text { of Liquid. }\end{array}$ & $\begin{array}{l}\text { Difference } \\
\mathrm{Cl}-\mathrm{H} \text {. }\end{array}$ \\
\hline $\mathrm{CH}_{4} \quad \ldots$ & I 8,900 & & - & - \\
\hline $\mathrm{CH}_{3} \mathrm{Cl}$ & 29,000 & & 33,900 & \\
\hline $\mathrm{CH}_{2} \mathrm{Cl}_{2}$ & $3 \mathrm{I}, 400$ & 2,400 & 37,800 & 3,900 \\
\hline $\mathrm{CHCl}_{3}$ & 46,600 & & 53,900 & \\
\hline $\mathrm{CCl}_{4} \ldots$ & 68,500 & & 75,700 & \\
\hline $\mathrm{C}_{2} \mathrm{H}_{6} \ldots$ & 23,300 & $I=800$ & - & - \\
\hline $\mathrm{C}_{2} \mathrm{H}_{5} \mathrm{Cl}$ & 39,100 & -4700 & 45,500 & $-4,500$ \\
\hline $\mathrm{C}_{2} \mathrm{H}_{4} \mathrm{Cl}_{2}$ & 34,400 & & $4 I, 000$ & \\
\hline
\end{tabular}

In the case of benzene the values for the solid substances are-

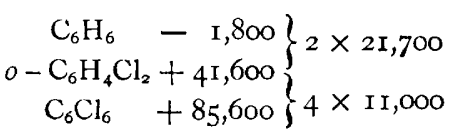

An examination of the above data shows that no additive relationship can be detected whether the compounds are compared in the gaseous, liquid, or solid state. The actual differences between the heats of formation of a hydrocarbon and its chloro-derivative vary from $+2 \mathrm{I}, 800 \mathrm{cal}$. on the one hand to $-4,700$ on the other. These differences are extraordinarily large and erratic when the simple character of the replacement is considered and form a remarkable contrast to the extreme regularity of the heats of formation of the metallic chlorides in dilute solution.

If the hydrocarbons alone are considered, similar irregularities are seen in the differences $\mathrm{CH}_{3}-\mathrm{H}$ and $\mathrm{C}_{6} \mathrm{H}_{5}-\mathrm{H}$ which are set out in Table IX.. and it is therefore evident that no analogue to the additive law of heats of formation of dissolved salts is found even in the most promising of the analogous cases.

* Landolt-Bornstein, pp. 416, 417. 


\title{
I36 THE THERMOCHEMISTRY OF ELECTROLYTES IN
}

\author{
TABLE IX.
}

Heats of Formation of Hydrocarbons.

\begin{tabular}{|c|c|c|c|c|c|}
\hline Substance. & $\begin{array}{c}\text { Heat of } \\
\text { Formation. }\end{array}$ & $\begin{array}{l}\text { Difference } \\
\mathrm{CH}_{3}-\mathrm{H} .\end{array}$ & Substance. & $\begin{array}{l}\text { Heat of } \\
\text { Formatien. }\end{array}$ & $\begin{array}{l}\text { Difference } \\
\mathrm{C}_{6} \mathrm{H}_{5}-\mathrm{H}\end{array}$ \\
\hline $\begin{array}{ll}\mathrm{CH}_{4} \text { (gas) } & \ldots . . . \\
\mathrm{C}_{2} \mathrm{H}_{6} \quad, \quad \ldots \ldots .\end{array}$ & $\begin{array}{l}18,900 \\
23,300\end{array}$ & \multirow{2}{*}{$\begin{array}{l}4,400 \\
7,200 \\
4,500\end{array}$} & $\begin{array}{l}\mathrm{CH}_{4} \text { (gas) } \ldots \\
\mathrm{CH}_{3} \mathrm{Ph} \quad, \cdots\end{array}$ & $\begin{array}{r}\text { I8,900 } \\
-5,400\end{array}$ & $-24,300$ \\
\hline $\begin{array}{lll}\mathrm{C}_{3} \mathrm{H}_{8} & , & \cdots \cdots \\
\mathrm{C}_{4} \mathrm{H}_{\mathrm{xo}} & , & \cdots \cdots\end{array}$ & 35,000 & & \multirow{2}{*}{$\begin{array}{l}\mathrm{CH}_{2} \mathrm{Ph}_{2} \text { (sol.) } \\
\mathrm{CHPh}_{3} \quad " \\
\mathrm{CPh} \quad "\end{array}$} & \multirow{2}{*}{$\begin{array}{l}-20,000 \\
-43,600 \\
-56,600\end{array}$} & \multirow{2}{*}{$\begin{array}{l}-23,600 \\
-13,000\end{array}$} \\
\hline $\mathrm{C}_{6} \mathrm{H}_{\mathrm{x}_{4}}$ (liq.) $\ldots \ldots$ & 57,600 & \multirow{2}{*}{2,200} & & & \\
\hline 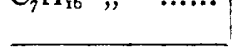 & 59,000 & & \multirow{2}{*}{$\begin{array}{ll}\mathrm{C}_{6} \mathrm{H}_{6} & \text { (sol.) } \\
\mathrm{C}_{6} \mathrm{H}_{5} \mathrm{Ph} & \prime \\
\mathrm{C}_{6} \mathrm{H}_{3} \mathrm{Ph}_{3} & \prime\end{array}$} & \multirow{2}{*}{$\begin{array}{l}-1,800 \\
-33,500 \\
-61,300\end{array}$} & \multirow{2}{*}{$\begin{array}{l}-31,700 \\
-13,900 \times 2\end{array}$} \\
\hline $\begin{array}{l}\mathrm{C}_{6} \mathrm{H}_{6} \quad \text { (liq.) } \\
\mathrm{C}_{6} \mathrm{H}_{5} \mathrm{CH}_{3} \quad ", \\
\mathrm{C}_{6} \mathrm{H}_{5}\left(\mathrm{CH}_{3}\right)_{2} \quad ",\end{array}$ & $\begin{array}{r}-4,100 \\
+2,300 \\
+15,100\end{array}$ & $\begin{array}{r}6,400 \\
\text { I } 2,800\end{array}$ & & & \\
\hline
\end{tabular}

The exactness with which the additive law holds good in the case of electrolytes is remarkable. With the exception of $\mathrm{H}_{2} \mathrm{~S}$ and $\mathrm{Ba}\left(\mathrm{NO}_{3}\right)_{2}$ the errors shown in Table $\mathrm{V}$. are in all cases less than one part in $\mathrm{I}, 000-\mathrm{a}$ tribute to the great accuracy of Thomsen's observations over a wide range, there being forty-four acids, bases, and salts included in the table. As regards the data for barium nitrate, it should be observed that Thomsen himself notes that there is an uncertainty in the barium values. With reference to the sulphides, we have assumed that in solutions of $\mathrm{K}_{2} \mathrm{~S}, \mathrm{Na}_{2} \mathrm{~S}, \& \mathrm{c}$., sulphur is divalent and the ion is simply $S$. The numbers given by Thomsen (II. 63) for $\mathrm{H}_{2} \mathrm{~S}$ in solution are (in ordinary notation)-

whence-

$$
\left(\mathrm{S}, \mathrm{H}_{2}\right)=4,740 \quad\left(\mathrm{H}_{2} \mathrm{~S}, \mathrm{Aq}\right)=4,560 ;
$$

$$
\left(\mathrm{H}_{2}, \mathrm{~S}, \mathrm{Aq}\right)=9,300 \text {, and } \frac{1}{2}\left(\mathrm{H}_{2}, \mathrm{~S}, \mathrm{Aq}\right)=4,650 \text {, }
$$

which is the figure tabulated for $\mathrm{H}_{2} \mathrm{~S}$ in Table III.

The divergence of this figure from the calculated value in Table IV. appears to indicate that $\mathrm{H}_{2} \mathrm{~S}$ in solution is only feebly ionised,* or possibly also that the ion containing sulphur in the solution $\mathrm{H}_{2} \mathrm{~S}$ is different from that in the salt solutions.

We have still to refer to the bracketed figure for $\mathrm{H} \mathrm{OH}$ in Table III.

The heat of combination of equivalents of water ions is identical with the heat of combination of equivalents of a strong acid and a strong base. As the best determined we may take the value for the heat of neutralisation of hydrochloric acid by soda given by Thomsen.

For the heats of formation of water from its elements we have-

$$
\mathrm{H}_{2}+\frac{1}{2} \mathrm{O}_{2}=\mathrm{H}_{2} \mathrm{O}+68,345 \text { cal., }
$$

* This view is confirmed by the heats of neutralisation :

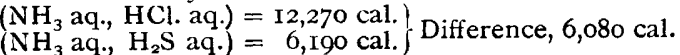




\section{RELATION TO HYDRATE THEORY OF IONISATION}

whilst its heat of formation from its ions is-

$$
\stackrel{+}{\mathrm{Haq}}+\mathrm{O} \overrightarrow{\mathrm{H}} \mathrm{aq}=\mathrm{H}_{2} \mathrm{O}+\mathrm{r} 3,740 \text { cal., }
$$

whence by subtraction-

$$
\mathrm{H}_{2}+\frac{1}{2} \mathrm{O}_{2}=\stackrel{+}{\mathrm{H}} \mathrm{aq}+\mathrm{O} \overline{\mathrm{H}} \mathrm{aq}+54,605 \mathrm{cal} \text {. }
$$

This number therefore represents the sum of the ionic heats of the $\mathrm{H}$ and $\mathrm{OH}$ ions, and it is that placed in Table III. in brackets.

This will perhaps be made clearer if we start with an imaginary mixture of equivalents of $\mathrm{H}$ and $\mathrm{OH}$ ions, the sum of whose heat values when uncombined is 54,605 . If they now combine, we have an added heat value of 13,740 . The result of this must be the heat value of water, viz., 68,345.

It will be seen that the figure 54,605 , which we thus obtain, falls into line, as a sum of ionisation heats, with the actual heats of the acids, bases, and salts.

\section{The Heats of Formation of the Ions in Relation to the HYDRATE THEORY OF IONISATION.}

The heats of formation of the ions as tabulated above represent the quantities of heat given out in the formation of one gram-equivalent of the hydrated ions from water and the separate constituents of the nucleus taken in the ordinary physical condition of these elements at the standard temperature $\left(18^{\circ} \mathrm{C}\right.$.). This definition is an agreement with the usual convention in reference to heats of formation, whereby, for instance, chlorine is taken in the gaseous, bromine in the liquid, and iodine in the solid state.

It will be noted at once that the heats of formation of the ions are complex quantities, and are made up of the algebraic sum of several distinct energy changes. In the case of the elementary ions, such as $\stackrel{+}{\mathrm{N}}, \stackrel{+}{\mathrm{Ba}}, \overrightarrow{\mathrm{C}}$, these are-

(I) The heat-change involved in the cleavage of the molecules of the element into their separate atoms.

(2) The heat-change involved in electrifying these atoms.

(3) The heat-change involved in the combination of the charged atoms or ionic nuclei with water.

In the case of ions derived from compound radicals, such as $\mathrm{NH}_{4}^{+}, \mathrm{NO}_{3}, \overrightarrow{\mathrm{SO}}_{4}$, a molecular cleavage must be supposed to occur in the case of each of the elements present in the ionic nucleus, but there is also superposed a fourth thermal change, namely-

(4) The heat-change involved in the combination of the constituent atoms of the radical.

Of these changes it is evident that (I) and (2) must normally be endothermic and involve an absorption of heat, whilst (3) and (4) will normally be exothermic and involve a liberation of heat. The heat of formation of an ion, therefore, always represents a difference, and the process of forming the ion from its elements and water will be exothermic or endothermic according as the sum of the heat-changes is positive or negative.

A low or negative heat of formation may be due-

(I) To a small heat of combination of the nucleus with water, as, for instance, in the case of the hydrogen ion.

(2) To a large absorption of heat in cleaving the elements of the nucleus into atoms; or 


\section{${ }^{3} 3^{8}$ THE THERMOCHEMISTRY OF ELECTROLYTES IN}

(3) To an abnormally large absorption of energy in electrifying the radical of the nucleus-c.g., in the case of a small ion, such as hydrogen, or a polyvalent ion such as $\stackrel{+++}{\mathrm{Fe}}$ or $\overline{\mathrm{PO}}_{4}^{-}$.

A large heat of formation may be due to much water-combination, or in the case of a polyatomic ion to a great heat of combination of the atoms of the nucleus.

In view of the large number of factors involved, it was hardly to be expected that the heats of formation of the ions would correspond with the degree of hydration, and, indeed, even if it were possible to determine separately the energy liberated by water-combination, there would be no reason for supposing that this energy would be wholly dependent on the quantity of water combined with the nucleus and independent of the nature of the nucleus. Thus it may be noticed that in the case of the acids the heat liberated in the combination of the anhydrous acid with one molecule of water is :-

$$
\begin{array}{ll}
\mathrm{H}_{2} \mathrm{SO}_{4}+6,380 \text { cal. } & \mathrm{C}_{2} \mathrm{H}_{4} \mathrm{O}_{2}-\mathrm{I}_{52} \mathrm{cal} . \\
\mathrm{HNO}_{3}+3,280 \text { cal. } & \mathrm{CH}_{2} \mathrm{O}_{2}+\mathrm{I}_{24} \mathrm{cal} .
\end{array}
$$

Again in the case of sulphur trioxide the heat liberated by the addition of successive molecular proportions of water is :-

$$
\begin{array}{ll}
\text { I. } 21,300 . & \text { 4. } 1,720 . \\
\text { 2. } 6,380 . & \text { 5- 6. } 985 \text { (average). } \\
\text { 3. } 3,040 . & \text { 7-10. } 932 \text { (average). }
\end{array}
$$

As indicating the extreme importance of water-combination as a source of energy it may further be noted that the heat of formation of sulphuric acid, $\mathrm{H}_{2} \mathrm{SO}_{4}$, by combination of its anhydride with water (2I,300 cal.) is almost exactly equal to the heat of formation of gaseous hydrogen chloride $(22,000$ cal.) from its elements. In each case a very large liberation occurs when the anhydrous acids thus produced are dissolved in water, and by a curious coincidence there is again an approximate numerical agreement ( 17,900 as against 17,300 cal.).

Although there does not appear to be any quantitative relationship between the heat of formation of an ion and the tendency of the element of which it is composed to assume the ionic state, it is noteworthy that hydrogen sulphide, the feeble ionisation of which has already been referred to, is the only compound in 'Table IV. which is composed of two ions, both of which have a negative heat of formation.

Water itself is probably another case of the same sort: the large heat of formation of the hydroxyl ion is due, as its mobility shows, very little to water combination and chiefly to the energy liberated in the combination of the oxygen and hydrogen atoms. Here again the tendency to ionisation is of the feeblest, and it is noteworthy that small coefficients of ionisation are far more frequent amongst the acids and bases than amongst the salts. The coefficient of ionisation is, however, a complex function since it depends not only on the stability or heat of formation of the ions but also on the stability of the undissociated molecules of the dissolved salt. The mere fact that a salt has a large tendency to absorb or combine with water does not, therefore, afford any a priori evidence that its solutions will be highly ionised. But it appears o be generally the case that an electrolyte will be only feebly ionised unless one of its ions has considerable affinity for water.

Finally, it may be noted that whilst the heat of formation of an ion in dilute solution is independent of the other ion associated with it, the degree of hydration, and therefore the heat of formation, may change when the concentration of the solution is increased. Further, there is no reason to 


\section{RELATION TO HYDRATE THEORY OF IONISATION 139}

suppose that any close relationship would exist between the heats of formation of ions in different solvents; in spite of the identity of the nucleus, the ions produced are quite distinct, and the energy of combination with the solvent would be entirely different when the solvent is changed. This is possibly the explanation of the widely different electrode potentials observed by Johnson and Wilsmore (Trans. Far. Soc., 1907, 1, 70-80) in liquid ammonia and in water. Similar considerations apply in the case of fused salts in which complexes such as-

$$
\stackrel{+}{\mathrm{K}}(\mathrm{KCl}) x \text { and } \stackrel{+}{\mathrm{K}}\left(\mathrm{KNO}_{3}\right) y
$$

may be expected to have quite different heats of formation. 